\title{
Hebben jeugdigen het nieuwe strafrecht verdiend?
}

D.A. Flinterman ${ }^{*}$

\section{De bende van Vinkhuizen}

"De bende van Vinkhuizen". Zo werd een groep jongelui vorig jaar in het Nieuwsblad van het Noorden en op Radio Noord afgeschilderd.

Op de zitting van 12 februari 1996 stonden de jongens voor mij terecht. De gedragingen waarvoor zij waren gedagvaard bestonden uit vernielingen van ongeveer 40 ruiten van een school, een basket en 129 winkelwagentjes van Aldi (schade $\pm f 23.000$ ). Ook werden graffiti, diefstal en vernieling van talloze fietsen, spiegels en emblemen van auto's ten laste gelegd. Het zwaarste delict waarvoor zij terechtstonden betrof het in elkaar slaan en trappen van enkele jongemannen, op een afgelegen plaats.

\section{Achtergronden}

De rapportages van de jeugdhulpverleners bieden inzicht in de persoonlijkheid van de jongeren en de gezinnen, waarin zij opgroeien. Uit deze rapportages blijkt over de verschillende daders onder meer het volgende:

- Over één van de jongens wordt gezegd dat hij niet genoeg body heeft, om de groep te beïnvloeden; er is sprake van meeloopgedrag; hij deed het voor de lol en om stoer te zijn; hij wilde geen watje zijn. Zijn ouders zijn gescheiden.

* Kinderrechter te Groningen 
- Onderliggende frustraties spelen een rol. Dit blijkt uit de motivatie van een andere jongen: deze jongen was op zoek naar agressieve vrienden; met zijn gewelddadige gedrag hoopte hij die te maken.

- De twee hoofddaders werden vroeger op school erg gepest. Zij verklaren dat zij een soort bevrediging voelden, nadat zij andere jongens in elkaar hadden geslagen. Daarnaast is er een aandachtstekort in de thuissituatie.- Ook wordt er melding gemaakt van een moeder, gescheiden, die erg inconsequent is in de opvoeding; haar nee wordt na enig zeuren altijd een $j a$.

- Eén van de jongens verklaart op de zitting dat hij bij de politie niet de volledige waarheid heeft verteld, omdat hij zich schaamde voor zijn ouders en voor zichzelf. Hij zegt: "Het is gewoonweg toch niet normaal wat we hebben gedaan. Maar", zegt hij "we werden ook nooit gewaarschuwd. De groep ging steeds verder, omdat wij nooit gepakt werden." En: "Thuis is het leven maar saai en vervelend. Daarom ging ik alcohol gebruiken en daardoor werd ik agressief." Persoonlijke problemen werden met de ouders niet besproken.

- Een andere jongen is ontevreden, mist zelfvertrouwen. Wordt depressief en vervolgens agressief. En alweer een gescheiden moeder, die zegt: "Eindelijk greep gelukkig de politie in. Eindelijk werden er grenzen gesteld. Want ik had wel vaag het idee dat er iets niet klopte."

- Een jongen, wiens vader overleden is en die erg vrij gelaten werd door zijn moeder, zegt dat hij net zo lang keet schopte in de klas en de leraren treiterde tot zij overspannen waren. De hulpverlening spreekt van een stoerheidssyndroom.

- En tot slot is er een jongen die nog erg kinderlijk is en een minderwaardigheidscomplex heeft. Zijn vader toont totaal geen interesse in hem. Zijn schoolverleden is een aaneenschakeling van mislukkingen.

Vormen de jongens, die ik hiervoor beschreef, nu een bende?

Ik heb ter zitting gezien, dat alle negen jongeren hele gewone aardige middelbare scholieren zijn. Het zouden onze kinderen kunnen zijn.

\section{De sancties}


Aan alle jongens heb ik de cursus Maten voor Maten, een sociale vaardigheidstraining van 30 uur, opgelegd en al naar gelang de hoeveelheid misdragingen bovendien een variërend aantal uren dienstverlening. Die dienstverlening hebben de jongens volgens het Nieuwsblad van het Noorden in de krokusvakantie ingevuld door fietstunneltjes schoon te maken.

In de cursus Maten voor maten is aandacht besteed aan de volgende vijf onderwerpen:

- vrije tijdsbesteding

- agressie/geweld

- positie slachtoffers

- verstevigen van goede invloed in groepsverband

- verstevigen van verantwoordelijkheidsgevoel

\section{Het nieuwe jeugdstraf(proces)recht}

Sinds 1 september 1995 hebben wij een nieuw jeugdstraf(proces)recht. Aan dit recht is gewerkt vanaf 1979. Drie doelstellingen stonden daarbij centraal. Dat waren:

\section{Jeugdrecht met een minder bevoogdend karakter}

Voorbeelden van elementen met een bevoogdend karakter waren het driehoeksoverleg tussen de kinderrechter, officier van justitie en Raad voor de kinderbescherming, de verschijningsplicht en de behandeling achter gesloten deuren. Dit soort elementen moest verdwijnen in verband met de toegenomen mondigheid van de minderjarige. Men wilde de minderjarige meer zien als zelfstandig individu met een eigen rechtspositie, dus als rechtssubject in plaats van als te beschermen rechtsobject. Hier valt een vergelijking te trekken met de wet BOPZ, waaruit het bestwilcriterium is verdwenen. Pas als het individu of de maatschappij gevaar loopt mag er door de overheid worden opgetreden. De gedachte hierachter is, dat het recht de persoonlijke vrijheid van een ieder moet garanderen, maar ook moet voorkomen dat de persoonlijke vrijheid van de één ten koste gaat van de ander.

\section{Vereenvoudiging}

Men wilde een beperking van de soorten sancties en waar mogelijk aansluiting bij het volwassenenstrafrecht. 


\section{Modernisering}

Een voorbeeld van modernisering is de wettelijke regeling van alternatieve sancties.

Het pedagogische karakter van de sancties diende overigens wel behouden te blijven. Vergelding en generale preventie mochten niet zover worden doorgevoerd, dat de minderjarige erdoor in zijn ontwikkeling zou worden geschaad.

\section{Vernieuwing, waarom?}

Opvallend is dat er in de periode van behandeling in de Tweede Kamer (1989-1993) nogal wat wijzigingen in het oorspronkelijke wetsvoorstel zijn aangebracht. Op vragen van CDA en PvdA of er sprake is van verharding in het strafrechtelijk optreden, wordt steevast geantwoord dat dat niet het geval is, maar dat men een vloeiender overgang naar het gewone strafrecht wil. De kinderrechter zou dan minder vaak hoeven uitwijken naar het volwassenenstrafrecht.

Mijns inziens hoefde de kinderrechter echter al helemaal niet vaak uit te wijken naar het volwassenenstrafrecht.

In de tweede Nota van Wijziging wordt de duur van de jeugddetentie verhoogd op verzoek van het $\mathrm{OM}$, om de afschrikkende werking van het jeugdstrafrecht in stand te houden. Door de staatssecretaris wordt de reeds bekende motivering aangevoerd, dat de rechter nu minder snel uit zal hoeven wijken naar het gewone strafrecht. Er wordt een voorbeeld aangehaald van een jongere onder de 16, die door oudere jeugdigen wordt overgehaald om criminele daden te verrichten, omdat die jongere onder de 16 toch geen hoge straf kan krijgen.

Of doelde men op de volgende zaken?

- Jonge kinderen, die door volwassenen worden ingezet als drugsrunners.

- Een jongen van 15 jaar, die door zijn Turkse vader en zijn oudste broer van 18 zodanig wordt bewerkt, dat deze uiteindelijk zijn lievelingszusje neersteekt; het zusje was te feministisch geworden en had ook geprobeerd haar moeder ertoe aan te zetten om haar onderdanige rol op te geven. 
- En andere kwesties van eer, uit een andere cultuur?

Is men in Nederland gezwicht voor de Turkse en Marokkaanse vaders, die kinderrechters soms smeekten om hun zonen stevigere straffen op te leggen bij diefstal en sommige vormen van geweldpleging, de gezichtsverliezende delicten. De hulpverlening had juist geadviseerd niet voor deze smeekbeden te zwichten.

Een ander argument dat men aanvoerde voor langere jeugddetentie, is dat men hierdoor oneigenlijk gebruik van de maatregel van plaatsing in een inrichting voor jeugdigen zou kunnen voorkomen. Dit is een vreemd argument, als we bedenken dat jeugdigen met een ondertoezichtstelling, met een maatregel van buitengewone behandeling en met een tuchtschoolstraf momenteel allemaal bij elkaar in dezelfde inrichting zitten.

Aan het in kaart brengen van de verschillende behandelingsmethodieken voor jeugdigen met specifieke problemen wordt door Justitie overigens hard gewerkt. Ook is men bezig om de centrale plaatsing van jeugdigen in landelijk opererende jeugdinrichtingen voor te bereiden. In de OGH te Zetten en De Heyacker in Breda experimenteert men met een geautomatiseerd systeem van plaatsing. Daarvoor is uiteindelijk een gestandaardiseerde indicatiestelling met objectieve gegevens nodig.

\section{Positieve ontwikkelingen}

Gelukkig veranderen er ook dingen ten goede. Ik ben blij met de ontwikkelingen in Groot Emaus, een orthopedagogisch behandelingsinstituut voor licht verstandelijk gehandicapte jongens en meisjes. Er komen steeds meer plaatsen voor besloten behandeling. Neem bijvoorbeeld ook de besloten eerste fase van een traject van BJ Brabant en het Centrum JPK te Den Haag. In Den Haag worden 16 plaatsen gecreëerd, waar psychiatrische behandeling van jeugdigen onder dwang kan plaatsvinden. Dagbehandeling in Den Haag kan als volwaardig alternatief voor de jeugdinrichting gelden. 
Een goede zaak is ook dat vorig jaar door Nederland het Verdrag voor de rechten van het kind is geratificeerd. Enerzijds heeft Nederland twee voorbehouden gemaakt bij dat verdrag (artt. 37 en 40):

- op kinderen van 16 jaar kan het volwassenenstrafrecht worden toegepast;

- delicten van lichte aard kunnen worden afgedaan zonder raadsman en zonder hoger beroep.

Anderzijds geldt wel het uitgangspunt dat het gebruik van gerechtelijke procedures waar mogelijk moet worden vermeden (art. 40). Bovendien moet bij het afhandelen van de jeugdcriminaliteit de reïntegratie van het kind in de maatschappij worden bevorderd.

Ik hoop dat de advocatuur en de hulpverleners in brede zin hun inspiratie in dit verdrag zullen zoeken, wanneer zij de belangen van de jeugd behartigen.

Nog een tweetal maatschappelijke ontwikkelingen dient hier vermeld te worden.

Ten eerste de toenemende kritiek op de werkwijze van de Raden voor de kinderbescherming, die heeft geleid tot rapporten van de commissie Vliegenthart en Gijsbers. Uit deze rapporten is onder andere wetgeving voortgekomen op het gebied van de ondertoezichtstelling, de lichtste kinderbeschermingsmaatregel. Onder invloed van de kritiek van de commissie en vooruitlopend op de nieuwe wetgeving is de werkwijze van kinderrechters veranderd.

Ten tweede is er de reorganisatie van de politie en de gedachte dat aanpak van de jeugd een taak is van de basiseenheid van de politie. Specialisme op jeugdgebied werd niet langer noodzakelijk geoordeeld. Van deze gedachte is men gelukkig aan het terugkomen. 


\section{Instanties}

Jeugdigen (12-18 jaar), die gedragingen verrichten, waarop het stempel crimineel kan worden gezet, kunnen in aanraking komen met de volgende instanties:

1 - politie in combinatie met Halt-bureau

2 - de officier van justitie

3 - de rechter

4 - de minister van Justitie of het ambtenarenapparaat.

Hierna worden de mogelijkheden van de bovenstaande instanties besproken.

\section{De Halt-afdoening (art. 77e Sr)}

De opsporingsambtenaar die daartoe door de officier van justitie is aangewezen kan met toestemming van de officier aan de jeugdige verdachte voorstellen om aan een Halt-project deel te nemen voor maximaal 20 uur; dit om te voorkomen dat het proces-verbaal naar het OM wordt gestuurd. De jeugdige verdachte kan er echter ook voor kiezen om het procesverbaal wel naar het OM te laten zenden.

Bij Algemene Maatregel van Bestuur zijn voor een Halt-afdoening als belangrijkste strafbare feiten aangewezen:

- vernielings-, brandstichtings- en vuurwerkdelicten (maximale schade van $f 1500$ per jeugdige)

- eenvoudige diefstal al dan niet in vereniging (waarde van het goed: maximaal $f 250$ ) en hierop gevolgde daden van heling en openlijk geweld tegen goederen.

In tegenstelling tot wat prof. Doek stelt, ben ik van mening dat het een goede zaak is dat de politie de toestemming van ouders of voogd nodig heeft om verdachten onder de 16 jaar naar een Halt-project te kunnen verwijzen. Sommige ouders hebben namelijk helemaal niet in de gaten wat hun kinderen uitspoken en kinderen houden bepaalde zaken liever voor hun ouders verborgen.

De Haltafdoening is bij de wet geregeld, valt onder verantwoordelijkheid van het O.M., kan bij AMvB uitbreiding ondergaan en de financiering van de afdoening ligt in handen van de gemeenten en het 
ministerie van Binnenlandse Zaken. Het staat gemeenten vrij om te bepalen of zij meedoen in het regionaal Halt-bureau of niet.

Door de officier van justitie in Groningen zijn per basiseenheid van de politie twee politieambtenaren aangewezen als aanspreekpunten voor de officier in jeugdzaken. Ook is afgesproken dat de jeugdige die met de politie in aanraking komt in alle gevallen óf wordt doorverwezen naar het Halt-bureau óf een proces-verbaal krijgt dat naar het OM wordt ingezonden. In het arrondissement Groningen is het ruime sepotbeleid van de politie met behulp van de zogenaamde puntenlijst dus verleden tijd. Het advies van de commissie Montfrans en de notitie Jeugdcriminaliteit liggen hieraan ten grondslag. Een beroep door de advocatuur op deze puntenlijst voor een niet-ontvankelijkheid van het OM heeft geen kans van slagen meer.

De Halt-afdoening bestaat, als er schade is, uit het vergoeden van die schade of een deel ervan, het verrichten van werkzaamheden voor de benadeelde, het maken van een werkstuk of een combinatie daarvan. Tot nu toe werd er voornamelijk naar het Halt-bureau verwezen voor vernielings- en vuurwerkdelicten. Jeugdigen die zijn opgepakt door de politie, worden niet zomaar weggestuurd, maar overgedragen aan hun ouders of verzorgers. Zo raken deze op de hoogte van wat hun kinderen hebben uitgehaald. Kinderen onder de 12 jaar, die in aanraking komen met de politie kunnen door de politie gemeld worden bij de Raad voor de kinderbescherming, de lokale hulpverlening dan wel de Centrale Meldpunten.

\section{Afdoening door de jeugdofficier (art $77 \mathrm{f} \mathrm{Sr}$ )}

Niet alleen de politie, maar ook de officier van justitie kan voorwaarden stellen ter voorkoming van strafvervolging (artt. 74 en $77 \mathrm{f}$ $\mathrm{Sr}$ ). Voor dit voorwaardelijke sepot is geen toestemming van de ouders nodig. De jeugdofficier heeft een beleid ontwikkeld dat hij afstemt met de kinderrechters, de Raad voor de kinderbescherming en de Werkstichting Jeugdbescherming, die zowel voogdij-, gezinsvoogdij-, als jeugdreklasseringstaken uitvoert. De voorwaarden die de jeugdofficier - thans gegrond op de wet, voorheen al deels praktijk - kan stellen, zijn: 
- dat de jeugdige zich zal richten naar de aanwijzingen van de Werkstichting Jeugdbescherming (art. 60 Wet op de Jeugdhulpverlening) voor een termijn van ten hoogste 6 maanden;

- dat de jeugdige arbeid ten algemene nutte of arbeid tot herstel van de door het strafbare feit aangerichte schade verricht, dan wel een leerprojekt volgt gedurende ten hoogste 40 uren binnen een termijn van ten hoogste 3 maanden. De verdachte dient een daartoe strekkend aanbod te doen en er dient een advies van de Raad voor de kinderbescherming omtrent de aard, de inhoud en de mogelijkheid tot tenuitvoerlegging van de aangeboden alternatieve sanctie te zijn;

- betaling van een geldsom aan de staat tot ten hoogste $f$ 5000,-

De officier van justitie wint altijd inlichtingen in bij de Raad voor de kinderbescherming omtrent de persoonlijkheid en de levensomstandigheden van de jeugdige verdachte, tenzij hij aanstonds onvoorwaardelijk van vervolging afziet of de zaak voor de kantonrechter vervolgt.

De hierboven genoemde alternatieve straffen worden ten uitvoer gelegd met behulp van het Bureau Taakstraffen Jeugdigen van de Raad voor de kinderbescherming, dan wel door de jeugdreklassering van de Werkstichting Jeugdbescherming.

Aan de jeugdige verdachte die geen raadsman heeft wordt op last van de voorzitter van de rechtbank ambtshalve een raadsman toegevoegd als:

- het OM een voorwaarde wil stellen en de taakstraf meer dan 20 uur zal bedragen

- het OM een geldsom vordert van meer dan $f 250$,-

- een vervolging is aangevangen wegens een feit waarvan in eerste aanleg de rechtbank kennis neemt.

Voldoet de jongere niet aan de door de officier van justitie gestelde voorwaarden, dan wordt hij gedagvaard voor de kinderrechter. De jeugdige verdachte kan een bezwaarschrift indienen tegen de dagvaarding; dit ter compensatie van het feit dat de kinderrechter uit het driehoeksoverleg is verdwenen.

Alhoewel de strafrechtelijke ondertoezichtstelling is verdwenen, kan de officier van justitie in civielrechtelijk kader wel weer een ondertoezichtstelling vorderen alsmede een machtiging voor een uithuis- 
plaatsing, als hij van mening is dat een minderjarige met ernstige zedelijke dan wel lichamelijke ondergang wordt bedreigd en vrijwillige hulpverlening faalt.

\section{Afdoening door de kinderrechter of de meervoudige strafkamer waaraan de kinderrechter deelneemt (art. $495 \mathrm{~Sv}$ )}

De officier van justitie brengt de zaak van een jeugdige verdachte aan bij de meervoudige kamer, als naar zijn aanvankelijk oordeel

- plaatsing in een inrichting voor jeugdigen dan wel

- een zwaardere vrijheidsstraf dan 6 maanden dient te worden opgelegd;

- de zaak ingewikkeld is;

- de zaak niet voor splitsing vatbaar is ingeval van meerdere verdachten en een of meer verdachten de leeftijd van 18 jaar heeft bereikt.

Thans ziet het er naar uit dat er vier keer per jaar een meervoudige strafkamer zitting moet plaatsvinden; per zitting zouden er dan ongeveer 4 à 5 zaken worden behandeld.

In het algemeen worden de zaken echter aangebracht bij de enkelvoudige strafkamer, voorgezeten door een kinderrechter.

Alhoewel men aanvankelijk de persoonlijke verschijningsplicht van de minderjarige verdachte had geschrapt, is deze plicht toch weer in de wet opgenomen. Bij niet verschijnen wordt de minderjarige opgeroepen met een bevel medebrenging. Verschijnt de verdachte weer niet, dan kan een veroordeling bij verstek plaatsvinden.

Verder worden zaken van minderjarigen toch weer achter gesloten deuren behandeld. Slechts als de kinderrechter van oordeel is dat het belang van de openbaarheid zwaarder weegt dan de bescherming van de persoonlijke levenssfeer van de verdachte, diens medeverdachte en wettelijke vertegenwoordigers, gelast hij een openbare behandeling.

Zelf ben ik een voorstander van meer openbaarheid. Maar nu men hiervan in de nieuwe wet is teruggekomen, denk ik dat wij een zaak van een minderjarige toch niet te snel in het openbaar moeten behandelen. 
Straffen voor jeugdigen (art. $77 \mathrm{~h} \mathrm{Sr}$ )

Welke straffen kunnen er nu aan minderjarigen worden opgelegd? De hoofdstraffen zijn:

- jeugddetentie met een maximum van één jaar en voor 16 - 18 jarigen tot twee jaar.

- geldboete tot een maximum van $f 5000,-$

In plaats van een hoofdstraf kunnen één of meer van de volgende alternatieve sancties worden opgelegd:

a. het verrichten van arbeid ten algemene nutte (maximaal 200 uur)

b. arbeid tot herstel van de aangerichte schade

c. een leerproject, waaronder bijvoorbeeld Slachtoffer in beeld $(25$ uur), het PAD project voor aan alcohol gerelateerde delicten, de cursus sexuele vorming (groep: 25 uur, individueel: 50 uur en de Sociale vaardigheidstraining: 30 uur).

Wordt er meer dan één alternatieve sanctie opgelegd, dan is het maximum 240 uur. In de praktijk worden ook combinaties van (voorwaardelijke) jeugddetentie en alternatieve sancties opgelegd.

En dan zijn er nog de bijkomende straffen. Dit zijn:

a. verbeurdverklaring

b. ontzegging van de rijbevoegdheid.

\section{Maatregelen}

Ten slotte kan de jeugdige een maatregel worden opgelegd. De maatregelen zijn:

a. plaatsing in een inrichting voor jeugdigen (art.77s Sr)

b. onttrekking aan het verkeer

c. ontneming van wederrechtelijk verkregen voordeel

d. schadevergoeding.

\section{Specialisatie}

Bij onze rechtbank worden jeugdigen, die ernstige delicten hebben begaan, voorgeleid bij de gewone rechter-commissaris, die dan optreedt als kinderrechter-plaatsvervanger. Ook de gevangenhoudingen worden behandeld in de gewone raadkamer, waaraan een kinderrechter-plaatsvervanger deelneemt. Mijns inziens is het niet 
bezwaarlijk dat er hier geen gespecialiseerde kinderrechter optreedt. De Raad voor de kinderbescherming, dan wel de jeugdhulpverlening in brede zin - inclusief (ortho)pedagogen, ontwikkelingspsychologen en kinderpsychiaters - behoren immers goede voorlichting te geven over de persoon van de jeugdige dader, zijn achtergrond en omstandigheden.

\section{Inrichting voor jeugdigen}

Voor plaatsing in een inrichting voor jeugdigen is gedragsdeskundige rapportage vanuit twee verschillende disciplines nodig. Wanneer bij de jeugdige tijdens het begaan van het feit een gebrekkige ontwikkeling of ziekelijke stoornis van de geestvermogens bestond, moet een van de gedragsdeskundigen een psychiater zijn. Het is te hopen dat kinderpsychiaters een heldere visie ontwikkelen omtrent het begrip gebrekkige ontwikkeling van de geestvermogens van een jeugdige. En dat zij een duidelijk advies zullen geven met betrekking tot een eventuele behandeling alsmede in welke instelling die behandeling het best kan worden ondergaan. De maatregel van plaatsing in zo'n instelling kan alleen worden uitgesproken door een meervoudige kamer. De maatregel kan bovendien slechts worden opgelegd als:

- er sprake is van een misdrijf, waarvoor voorlopige hechtenis is toegelaten

- de veiligheid van anderen, dan wel de algemene veiligheid van personen of goederen het opleggen van die maatregel eist

- de maatregel in het belang is van de verdere ontwikkeling van de verdachte.

Indien jeugddetentie of plaatsing in een inrichting voor jeugdigen wordt opgelegd, neemt de rechter in zijn uitspraak een advies op over de plaats waar en de wijze waarop de straf of maatregel ten uitvoer wordt gelegd. Het verdient mijns inziens aanbeveling - gezien het bepaalde in art. 77v $\mathrm{Sr}$ - dat de Raad voor de kinderbescherming bij de ouders informeert naar de plaats waar de gezaghebbende ouder de straf of de maatregel bij voorkeur geëxecuteerd ziet; de Raad zou verder moeten informeren naar de levensbeschouwelijke overtuiging van de jeugdige. 
De duur van de maatregel van plaatsing is maximaal 2 jaar, eenmaal te verlengen met weer maximaal 2 jaar. In geval van een gebrekkige ontwikkeling of ziekelijke stoornis is de maximale termijn 6 jaar.

\section{De minister van Justitie}

Met betrekking tot de minister van Justitie wil ik hier een aantal relevante bepalingen noemen.

Ten eerste art. 77v Sr. De minister draagt de tenuitvoerlegging van de maatregel op aan een rechtspersoon als bedoeld in art. 60 Wet op de Jeugdhulpverlening of hij laat de veroordeelde opnemen in een tehuis, behorende tot de categorie, genoemd onder II, onderdelen 3 of 4 van de bijlage behorende bij die wet, voorzover dit door de minister in stand wordt gehouden, of elders. De minister kan de maatregel te allen tijde, na advies van de Raad voor de kinderbescherming te hebben ingewonnen, voorwaardelijk of onvoorwaardelijk beëindigen.

De jeugddetentie wordt ten uitvoer gelegd in een rijksinrichting of in een daartoe door de minister gesubsidieerde voorziening als bedoeld in art. 65 van de Wet op de jeugdhulpverlening, voor zover deze daartoe is bestemd krachtens artikel 66 van die wet.

De minister van Justitie beslist uiteindelijk over de plaats van tenuitvoerlegging van de detentie of plaatsingsmaatregel. Daarbij let de minister op het advies van de rechter die de veroordeling uitsprak, de wens van degene die het gezag uitoefent en de godsdienstige of levensbeschouwelijke overtuiging van de jeugdige persoon. De beslissing kan later worden gewijzigd, als bijzondere omstandigheden daartoe aanleiding geven. De minister kan altijd het advies van de Raad voor de kinderbescherming inwinnen omtrent de plaats van de tenuitvoerlegging.

De veroordeelde kan beroep instellen tegen een beslissing van de minister omtrent de plaats van tenuitvoerlegging bij het College van advies voor de justitiële kinderbescherming, bedoeld in artikel 81 van de Wet op de jeugdhulpverlening.

Justitie heeft op dit moment 381 plaatsen voor opvang van jeugdigen en 612 plaatsen voor behandeling. 
In Groningen wordt standaard door de rechter-commissaris bepaald dat de voorlopige hechtenis zal worden ondergaan in een voor minderjarigen geschikte inrichting, dan wel desnoods uiterlijk tot 6 dagen na ingang van het gegeven bevel in een politiebureau. Binnen deze termijn van 6 dagen, welke termijn ook voor de volwassenen wordt gehanteerd, moet het OM zien te regelen dat er plaats is in een jeugdopvanginrichting. Die plaats is er meestal niet. De aanmeldingen worden centraal geregistreerd in Den Haag en op volgorde van binnenkomst afgehandeld. De meeste jeugdigen komen dus uit plaatsen waar men hen het langst in een politiecel laat zitten. In Middelburg laat men een jeugdige in het geheel niet in een politiecel zitten, terwijl in Leeuwarden de jeugdige langer in een politiecel verblijft dan 6 dagen.

Ook hiervoor is men landelijke criteria aan het ontwikkelen.

Bij de maatregelen van schadevergoeding aan het slachtoffer (Terwee) en de ontnemingsvordering (Pluk ze) zijn veel vraagtekens te zetten. Vooral met betrekking tot de manier waarop deze thans worden behandeld door het OM, de politie en het bureau slachtofferhulp en tenslotte op de zitting. Sommige vertoningen lijken op het eerste gezicht een belediging van de benadeelde partij. Bovendien vraag ik mij af of wij - als wij een volledige genoegdoening nastreven - met deze maatregelen niet te dicht tegen de vergelding aan zitten; dat was immers juist niet de bedoeling in het nieuwe jeugdstrafrecht.

Beide maatregelen zijn bovendien niet bepaald pedagogisch, wanneer de jeugdige verdachte geen cent heeft en daarop ook voorlopig geen uitzicht heeft.

Verder wil ik nog opmerken dat de mogelijkheid om op 16- tot 18jarigen het meerderjarige strafrecht toe te passen verruimd is. Behalve de ernst van het feit en de persoonlijkheid van de dader, wordt als

nieuw criterium ingevoerd de omstandigheden waaronder het feit is gepleegd.

\section{Tot besluit}

Laat mij tot slot weer enkele jeugdige verdachten ten tonele voeren, die recentelijk voor mij verschenen: 
- Een Antilliaanse jongen van 16 jaar. Samen met een oom heeft hij talloze diefstallen gepleegd. Zijn moeder was 16 jaar toen hij geboren werd. Afwisselend heeft hij in een tehuis verbleven of bij zijn oma gewoond. Als zijn oma remigreert naar de Antillen, komt zijn moeder over naar Nederland, maar zij blijkt geen enkele greep op hem te hebben.

- Een Antilliaanse jongen van 17 jaar, die te horen krijgt "ga terug naar je eigen land" en die er vervolgens te hard op losslaat.

- Een Surinaamse jongen van Javaanse afkomst, 16 jaar oud. Met zijn ouders 2 maal verhuisd van Suriname naar Nederland. Verwijderd van zijn school vanwege opvoedings-en drugsproblematiek. Samen met een groep Antilianen heeft hij een pillendealer in elkaar geslagen, omdat deze op zijn beurt één van hen zou hebben geslagen.

- Een Antilliaanse jongen van 16 jaar, die samen met drie vriendjes een jackmove heeft gepleegd. Op geen enkele school is hij nog welkom.

- Een 15-jarige Nederlandse jongen, die op een kerkhof samen met anderen vernielingen heeft aangericht. Hij had geen idee, dat er op dat kerkhof mensen begraven lagen. Als mensen doodgingen, werden ze toch gecremeerd. En op het kerkhof was het lekker donker, daar kreeg je alleen al een kick van.

- Een Somalische jongen, die een meisje zou hebben aangerand. Maar het meisje bleef gewoon met haar fiets bij hem stil staan, dus wilde zij toch wel gekust worden. Zij had niet hoeven afstappen van haar fiets, toen hij haar in het Engels begroette.

- Een stel Nederlandse jongens die naar de flikkerbult in het Noorderplantsoen gaan om flikkers in elkaar te slaan; als die niet komen opdagen, gaan zij op zoek naar andere geschikte figuren, studentachtige types, te herkennen aan kleding en haardracht.

- Twee alleenstaande minderjarige asielzoekers, door de Stichting Opbouw op kamers geplaatst in de stad. Eenmaal per maand krijgen zij bezoek van hun voogd. Zij plegen in een park een overval en hun eerste slachtoffer blijkt niet bang te zijn, dus gaan zij er mee door. Zij denken alleen maar aan zichzelf, hebben ook geen idee, want nooit ervaren wat en hoe de ander voelt. 
Zijn de gedragingen van de jeugdigen verhard? Of is de tolerantie van de volwassenen geringer geworden? Is het kind meer verwend en daardoor egoïstischer, normlozer, gewetenlozer geworden? Of hebben de volwassenen niet het goede voorbeeld gegeven, is de begrenzing, sturing te gering geweest? Is er sprake van onvrede bij kinderen, hebben zij geen perspectief gekregen, geen verantwoordelijkheden? Er is een groot aantal onthechten in onze maatschappij. Ik noem adoptiekinderen, alleenstaande minderjarige asielzoekers, Antillianen en Surinamers die aan hun lot overgelaten zijn, tweede- generatie Turkse en Marokkaanse kinderen, die onthecht zijn van de éne en niet gehecht zijn aan de andere cultuur, kinderen van gescheiden ouders, verwaarloosde, verwende en van scholen verwijderde kinderen. Cijfers van het WODC laten echter zien dat er geen toename is van criminaliteit onder jeugdigen. Het gaat eigenlijk heel goed met de Nederlandse jeugd. Met een kleine groep jeugdigen gaat het alleen steeds slechter en die problematiek los je mijns inziens niet op door een steeds harder jeugd straf(proces)recht.

Toen ik voor het eerst als rechter in strafzaken moest optreden en aan de toenmalige president van de rechtbank te Zwolle, mr Fliek vroeg hoe je in hemelsnaam de strafmaat moest bepalen zei hij: "Lees de krant maar en let op de uitspraken van je collegarechters in strafzaken". Zo gaat dat dus. En omdat wij allemaal de kranten blijven lezen, neemt de strafmaat toe. Maar als kinderrechter blijf ik volhouden, dat de criminaliteit onder de jeugdigen niet toeneemt; hoogstens die onder volwassenen. 